\title{
Quality of care for type 2 diabetes mellitus in Tripoli Medical Center: a retrospective study of 628 patients
}

\section{ABSTRACT}

Introduction. Diabetes mellitus (DM) is a major public health problem. Evidence has shown that aggressive control of hyperglycemia and associated risk factors reduces the risk of both macrovascular and microvascular complications. The aim of this study was to determine the proportion of diabetes patients reaching the targets recommended by The American Diabetes Association (ADA) standards for diabetes care.

Methods and materials. This is a retrospective study, conducted at the diabetes outpatient clinics at TMC. For 628 patients with diabetes with at least two clinic visits in the 24 months before August 2010, we assessed measurement and control of $\mathrm{HbA}_{1 \mathrm{c}^{\prime}}$ blood pressure, and lipid, the data were collected in a specially designed data sheet, and analyzed using SPSS program.

Results. 628 patients were studied. The mean age was $49.6 \pm 11.8$ years; average duration of diabetes was $6.5 \pm 5.0$ years. The mean last $\mathrm{HbA}_{1 \mathrm{c}}$ was $8.2 \pm 2.4 \%$. $75.1 \%$ attained a systolic blood pressure of $<140$ and $75.7 \%$ attained a diastolic blood pressure of $<90 \mathrm{~mm} \mathrm{Hg}$. Only $30.8 \%$ had LDL cholesterol of $<100 \mathrm{mg} / \mathrm{dL}$ and $49.0 \%$ had a triglyceride level of $<150 \mathrm{mg} / \mathrm{dL}$. The rate of annual foot examination, retinal examination

Address for correspondence:

Professor Hawa Juma El-Shareif

Endocrine Department, Tripoli Medical Center

(Tripoli University for Medical Sciences, Faculty of Medicine),

Tripoli, Libya

e-mail: hawa_elsharif@yahoo.com

Clinical Diabetology 2017, 6, 6, 204-210

DOI: $10.5603 /$ DK.2017.0033

Received: 13.01.2018

Accepted: 15.01.2018 screening, and urine microalbumin screening were low. Conclusions. This study demonstrates a low rate of diabetes care targets achievement among patients with type 2 diabetes treated at TMC. (Clin Diabetol 2017; 6, 6: 204-210)

Key words: glycemic control, diabetes type 2, Libya, TMC, targets, standards, quality of care, tertiary care

\section{Introduction}

Diabetes mellitus (DM) is a major public health problem that is growing rapidly throughout the world, and its incidence is approaching epidemic proportions [1]. According to the International Diabetes Federation's (IDF) statistics released, as many as $80 \%$ of people with diabetes live in developing countries, where, population growth, ageing and, urbanisation with dramatic changes in lifestyle all contribute to the dramatic pace of the epidemic [2].

The prevalence of diabetes mellitus in Libya is not precisely known, although it has been estimated to be as high as $14.1 \%$ [3]. The prevalence of type 2 diabetes and impaired glucose regulation reported in a Libyan population based stepwise survey, which assessed the prevalence of cardiovascular risk factors among Libyans aged 25-64 was $23.7 \%$ [4].

Diabetes has been associated with chronic metabolic conditions such as obesity and metabolic syndrome, as well as related macrovascular and microvascular complications, such as coronary artery disease, peripheral vascular disease, stroke, diabetic neuropathy, renal failure and blindness $[5,6]$. Diabetic complications result in significant disability, reduce life 
expectancy and impose an enormous burden on socioeconomic and public health care systems [7-10]. Direct medical costs consist of resources used to manage the disease. Indirect costs include lost productivity caused by morbidity, disability and premature mortality $[9,10]$.

Hypertension, obesity, hyperlipidaemia and smoking are important atherosclerotic risk factors which are more prevalent in diabetic patients and contribute to their high mortality compared with non-diabetic patients [11, 12]. Several clinical trials have demonstrated that intensive glycemic control effectively delays the onset and slows the progression of diabetic complications, such as nephropathy, retinopathy, and neuropathy $[13,14]$. Likewise, strong evidence has shown that aggressive control of associated risk factors such as hypertension, and hyperlipidemia reduces the risk of both microvascular and macrovascular complications $[15,16]$. In addition, early detection of complications, by systematic annual screening, allows early diagnosis and early intervention [17-20]. The American Diabetes Association (ADA) recommends a set of diabetic care standards that advocate aggressive management of hyperglycemia, hypertension, and hyperlipidemia for patients with diabetes [21]. Despite the publication of the ADA and other guidelines, several studies have reported suboptimal target achievement and care provided to people with diabetes based on evidence-based quality of care standards $[22,23]$.

The aim of this study was to determine the proportion of diabetes patients reaching the targets recommended by the ADA standards for diabetes care.

\section{Methods and materials}

This is a retrospective study, conducted at the diabetes outpatient clinics at the Tripoli Medical Center (TMC), a tertiary care center. Data collection was carried out in August and September 2010. The records of the first registered diabetic patients at the TMC diabetes clinic were reviewed. Patients were eligible for inclusion if they were of Libyan nationality, had type 2 diabetes, according to their medical records, and had at least two visits to the study clinic in the 24 months before August 2010. A total of 713 patients was included.

Information about patient demographic characteristics, smoking history, education, employment, duration of diabetes, presence of complications and the prescribed medication including lipid-lowering therapy and aspirin usage. Data for the most recent clinic visit were obtained using a chart review form. The following variables were assessed: height, weight, and blood pressure measurements during the most recent visit. Body mass index (BMI) was calculated using the formula: weight $(\mathrm{kg}) /$ height $\left(\mathrm{m}^{2}\right)$. Aoutcome of foot examination, retinal examination, and urine microalbumin screening performed in the prior year were recorded. The last measured value of $\mathrm{HbA}_{1 \mathrm{c}^{\prime}}$ creatinine level, LDL cholesterol (LDL-C), HDL cholesterol (HDL-C), triglyceride, and total cholesterol were collected. Also, frequency of performing these measurements within the prior year follow-up was assessed.

The targets used for this study were those specified by the ADA guidelines, namely $\mathrm{HbA}_{1 \mathrm{c}}<7 \%$, LDL-C $\leq 100$ $\mathrm{mg} / \mathrm{dL}, \mathrm{HDL}-\mathrm{C} \geq 40 \mathrm{mg} / \mathrm{dL}$, total cholesterol $\leq 200 \mathrm{mg} / \mathrm{dL}$, triglycerides $\leq 150 \mathrm{mg} / \mathrm{dL}$, systolic blood pressure $\leq 130 \mathrm{~mm} \mathrm{Hg}$, and diastolic blood pressure $\leq 80 \mathrm{~mm} \mathrm{Hg}$, fasting blood glucose $(F B G) \leq 130 \mathrm{mg} / \mathrm{dL}$.

Data were analyzed using the Statistical Package for Social Science (SPSS Inc., IBM, US), 19 th version. Continuous variables are expressed as mean \pm standard deviation (SD) and range. Categorical data are expressed as numbers and percentages. Student's t-test was used to compare continuous variables and qualitative variables were analyzed with the chi-square test or Fisher's exact test. This study was carried out in accordance with the principles of the Helsinki Declaration. A formal approval was obtained from institutional authorities.

\section{Results}

The clinical characteristics of the 628 patients is as follows: mean age was $49.6 \pm 11.8$ years (18-81), 294 $(46.8 \%)$ were males, the mean disease duration was $6.5 \pm 5.0$ years (range 1-34) and $300(47.8 \%)$ had a positive family history of diabetes.

Smoking history was available for 442 (70.4\%) of patients, where 69 (15.6\%) were current smoker, $28(6.3 \%)$ were ex-smoker and 345 (78.1\%) were non smokers. 67 (97.1\%) of current smokers were males.

Body weight and height were documented for 370 (58.9\%) patients, mean BMI was $30.8 \pm 8.4$. Only 76 patients (20.5\%) had a BMI $<25 \mathrm{~kg} / \mathrm{m}^{2}, 118$ patients (31.9\%) were overweight with a BMI between 25-29 $\mathrm{kg} / \mathrm{m}^{2}$ and 176 patients (47.6\%) were obese with a $\mathrm{BMI} \geq 30 \mathrm{~kg} / \mathrm{m}^{2}$.

Approximately 204 (32.5\%) of patients had been on insulin, either alone or in combination with oral hypoglycemic agents (OHA), 292 (46.5\%) were on metformin either alone or in combination with insulin and/ /or sulfonyleurea. 238 (37.9\%) were on sulfonyleurea either alone or in combination with basal insulin and/ lor metformin.

Table 1 summarize the proportion of patients for whom the aspect of care have been documented in their medical records.

The mean fasting blood sugar was $195.0 \pm 79.5$ $\mathrm{mg} / \mathrm{dL}$ (range $31-721$ ). $\mathrm{HbA}_{1 \mathrm{c}}$ results in the previous 
Table 1. The aspect of care documented in medical records at last visit

\begin{tabular}{lccc}
\hline Variable & No. $(\%)$ & Variable & No. (\%) \\
\hline Weight & $543(86.5)$ & Triglyceride & LDL cholesterol \\
BMI & $370(58.9)$ & HDL cholesterol & $312(49.3)$ \\
Systolic blood pressure & $569(90.6)$ & Urea and/or creatinine & $311(49.5)$ \\
Diastolic blood pressure & $569(90.6)$ & Microalbuminuria & 319 (50.8) \\
Fasting blood glucose & $519(82.6)$ & Annual dilated fundus examination \\
HbA $_{1 c}$ & $371(59.1)$ & & 20 (3.2) \\
Total cholesterol & $393(62.6)$ & \\
\hline
\end{tabular}

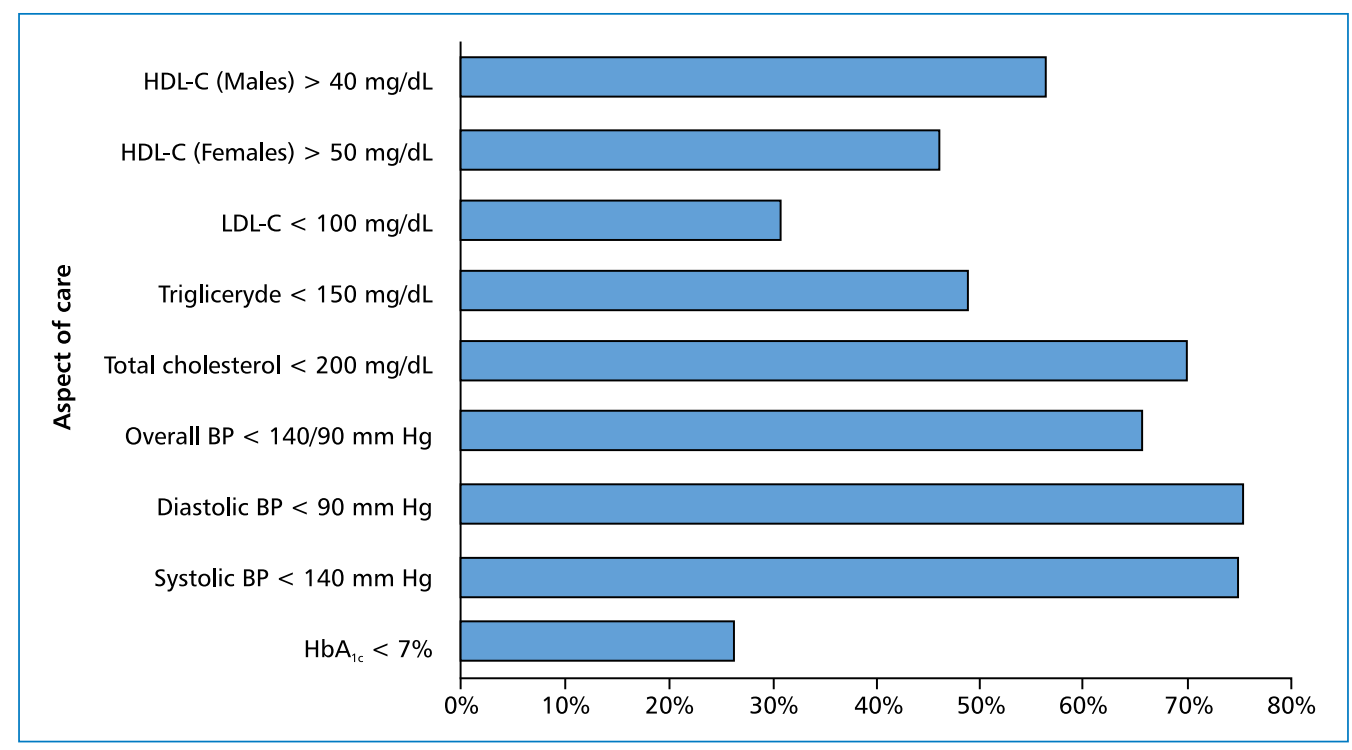

Figure 1. Proportion of patients with type 2 diabetes mellitus reaching the targets of ADA standards of medical care in diabetes at Tripoli Medical Center. BP — blood pressure

year were available for 371 (59.1\%) patients and a mean frequency of testing was $1.5 \pm 0.8$ (range 1-5). The mean last $\mathrm{HbA}_{1 \mathrm{c}}$ carried out for them was $8.2 \pm$ 2.4\% (range 4.0-16). 98 (26.4\%) achieved the recommended goals for both blood glucose $\left(\mathrm{HbA}_{1 \mathrm{c}}<6.5 \%\right)$, $57(15.4 \%)$ achieved $\mathrm{HbA}_{1 \mathrm{c}}<7.5 \%$, but more than $6.5 \%$, and $62(16.7 \%)$ achieved $\mathrm{HbA}_{1 \mathrm{c}} 7.5-<8.5$ and in $154(41.5 \%)$ the $\mathrm{HbA}_{1 \mathrm{c}}>8.5 \%$.

Documentation of blood pressure measurement was available for 570 (90.8\%). The mean systolic blood pressure was $125.9 \pm 17.2$ (range $85-200$ ) $\mathrm{mm} \mathrm{Hg}$, and the mean diastolic blood pressure was $79.6 \pm 9.4$ (range 50-110) $\mathrm{mm} \mathrm{Hg}$.

The distribution of patients' systolic blood pressure was: 428 (75.1\%) ones with $<140 \mathrm{~mm} \mathrm{Hg}$, and 142 (24.9\%) ones with > $140 \mathrm{~mm} \mathrm{Hg}$ (Fig. 1). The distribution of patients' diastolic blood pressure was:
431 (75.7\%) ones with < $90 \mathrm{~mm} \mathrm{Hg}$ and 138 (24.3\%) ones with $\geq 90 \mathrm{~mm} \mathrm{Hg}$.

$110(17.5 \%)$ were on statins, 287 (45.7\%) were on aspirin and 62 (9.9\%) were on ACE inhibitors. The number of follow up in the previous year was $1.4 \pm$ 1.6 (range 0-7); 64 (10.2\%) had peripheral neuropathy (PNP) based on symptoms or clinical examinations, 27 (4.3\%) had retinopathy, documentation of annual eye's fundus examination available in 20 (3.2\%). Symptoms of claudication were present among 14 (2.2\%) patients. Examination of peripheral blood vessels done among $4(0.6 \%)$ patients. Two patients $(0.3 \%)$ had a history of amputations and 28 (4.5\%) ones had ischaemic heart disease in the form of stable angina. Annual testing for protein urea was available among $43(6.8 \%)$ patients. Results of blood urea and creatinine levels was available among 319 (50.8\%) patients. 
Results of total cholesterol, TG, HDL-C, LDL-C were available among 393 (62.6\%), 404 (64.3\%), 311 (49.5\%), 312 (49.7\%) of patients' files respectively. In those with available results, the mean serum total cholesterol was $187.4 \pm 72.5$ (101-973) mg/dL. 277 patients $(70.0 \%)$ had a total cholesterol $<200 \mathrm{mg} / \mathrm{dL}$. The mean total serum triglyceride value was 170.4 \pm 104.9 (40-937) mg/dL. 196 patients (49.0\%) had a triglyceride level of $<150 \mathrm{mg} / \mathrm{dL}$. Mean high density lipoprotein cholesterol (HDL) level was $47.4 \pm 12.9$ (14.5-84.6) $\mathrm{mg} / \mathrm{dL}$. Only 80 female patients (46.2\%) and 78 male patients (56.5\%) had HDL level above the recommended of $50 \mathrm{mg} / \mathrm{dL}$ and $40 \mathrm{mg} / \mathrm{dL}$. Low density lipoprotein cholesterol (LDL) level was $123.4 \pm 50.6$ (37.4-452) $\mathrm{mg} / \mathrm{dL}$. Only seventy 96 patients (30.8\%) had LDL cholesterol of $<100 \mathrm{mg} / \mathrm{dL}$ (Figure 1).

\section{Discussion}

Diabetes is a chronic metabolic condition, which is associated with increased morbidity, disability, and mortality, largely due to microvascular complications such as nephropathy, retinopathy and neuropathy and macrovascular complications such as coronary artery disease, peripheral vascular disease and stroke [6, 7].

Several clinical trials have shown that intensive glycemic control and the associated CV risk factors such as hypertension, and hyperlipidemia in diabetic patients reduces the risk of both microvascular and macrovascular complications [13-16].

Despite the broadly distributed diabetes care guidelines, which give clear recommendations to the glycemic, blood pressure and lipid targets in diabetic patients, several studies have indicated that achievement of these targets is suboptimal [22-25].

In the present study, only $59.1 \%$ of patients had at least one $\mathrm{HbA}_{1 \mathrm{c}}$ test results available in their files, during the year prior to last visit. The frequency of testing during that year was $1.5 \pm 0.8$.

Regular $\mathrm{HbA}_{1 \mathrm{c}}$ measurement is important for effective diabetes management. $\mathrm{HbA}_{1 \mathrm{c}}$ reflects the average level of blood glucose over approximately 3 months and has strong predictive value for diabetes complications. ADA recommendation is to perform the $A 1 C$ test at least two times a year in patients who have stable glycemic control and more frequently in patients who are not meeting glycemic goals. $\mathrm{HbA}_{1 \mathrm{c}}$ measurement is an essential indicator for optimal quality of diabetes care. Studies have found an association between adherence to $\mathrm{HbA}_{1 \mathrm{c}}$ measurement and quality outputs [26-28].

Data from Kuwait found that doubling of the $\mathrm{HbA}_{1 \mathrm{c}}$ measurements (from $30 \%$ to $63 \%$ ) between 2010 and 2012, was associated with a decrease in the rate of poorly controlled $\mathrm{HbA}_{1 \mathrm{c}}$ from around $80 \%$ to $55 \%$ [29]. Our findings regarding glycemic control are comparable with those of studies in other Arab countries, $26.4 \%$ patients achieved $\mathrm{HbA}_{1 \mathrm{c}}<6.5 \%$ and $41.8 \%$ ones achieved $\mathrm{HbA}_{1 \mathrm{c}}<7.5 \%$. In a study from a university health center in Lebanon, target goal for $\mathrm{HbA}_{1 \mathrm{c}}$ of $<7 \%$ was met in $28.4 \%$ individuals [30]. In a study from Saudi Arabia tertiary care hospital in Riyadh only $21.8 \%$ patients achieved $\mathrm{HBA}_{1 \mathrm{c}}<7 \%$ [31]. Another study conducted in 28 Saudi health centers, all over the country, only $27 \%$ of patients achieved the target level of $\mathrm{HbA}_{1 \mathrm{c}}$ of $<7 \%$ [32]. A study from a tertiary care setting in UAE in 2008 , found that only $20 \%$ achieved the target of $\mathrm{HbA}_{1 \mathrm{c}}$ in that year [33].

In the present study, $41.5 \%$ of patients had $\mathrm{HbA}_{1 \mathrm{c}}$ above $8.5 \%$, this is less than the $54 \%$ reported in a study looking at diabetics in primary care settings in Saudia, and the $55.4 \%$ reported rate for poor control in Kuwait [29, 34].

Major clinical trials have shown that the target $\mathrm{HbA}_{1 \mathrm{c}}$ goal, is difficult to maintain in clinical practice. According to the National Health and Nutrition Examination Survey (NHANES IV) 1999-2000, only 37\% of participants with previously diagnosed diabetes achieved the target $\mathrm{HbA}_{1 \mathrm{c}}$ goal of less than 7.0\% [35]. In the United Kingdom Prospective Diabetes Study (UKPDS) $\mathrm{HbA}_{1 \mathrm{c}}$ of $7.0 \%$ was achieved in only $50 \%$ of patients [36]

Barriers to achieving optimal glycemic goal include poor-compliance to diet, exercise and medications, lack of educations as well as cultural barriers. Clinical inertia may also contribute to it $[37,38]$

In Tripoli medical center, diabetes outpatient clinic, the nurses are responsible for blood pressure and body weight measurement, on each visit before the consultation. $570(90.8 \%)$ of our patients had their BP documented, this rate is comparable to other studies, where more than $85 \%$ of patients attending the diabetic clinic had their blood pressure checked regularly [22, 23, 30, 39].

Blood pressure control is associated with significantly lower risk of mortality, cardiovascular events, coronary heart disease, stroke, albuminuria, and retinopathy $[6,12,15,17,19]$. Previous ADA guidelines recommended strict blood pressure target of $<130 / 80 \mathrm{~mm} \mathrm{Hg}$ in diabetic patients. In the Action to Control Cardiovascular Risk in Diabetes Blood Pressure (ACCORD-BP) trial, blood pressure reduction to $<120 \mathrm{~mm} \mathrm{Hg}$ compared with < $140 \mathrm{~mm} \mathrm{Hg}$, did not reduce mortality or overall cardiovascular outcomes, but significantly reduce stroke risk [40]. The current ADA recommendation is to achieve blood pressure levels $<140 / 90 \mathrm{~mm} \mathrm{Hg}$ to reduce cardiovascular disease (CVD) mortality and slow chronic kidney disease progression [21]. 
In the present study, the overall, systolic and diastolic blood pressure goals of $<140 / 90 \mathrm{~mm} \mathrm{Hg}$ were achieved in $65.8 \%, 75.1 \%, 75.7 \%$ patients respectively. $29.0 \%$ patients achieved both systolic and diastolic blood pressure targets of $<130 / 80 \mathrm{~mm} \mathrm{Hg}$. In a study from Lebanon systolic and diastolic blood pressure goals of $135 / 85 \mathrm{~mm} \mathrm{Hg}$ were met in $55.4 \%, 65.7 \%$, of their studied patients [30]. In a study from a tertiary care center in Saudi Arabia, involving 1188 diabetic patients the overall, systolic and diastolic blood pressure goals of $<130 / 80$ were achieved in 39.0, 47.6 and $74.6 \%$ of diabetic patients respectively [31].

Blood pressure control in diabetic patients is often challenging, and most patients with diabetes and hypertension require multiple-drug therapy to achieve blood pressure treatment goals $[15,21]$. Only $35.8 \%$ of the people with diabetes that participated in the NHANES 1999-2000 survey reached the target of systolic blood pressure $\leq 130 / 80 \mathrm{~mm} \mathrm{Hg}$ [35].

Several factors can contribute to poor blood pressure control, clinical inertia, with the failure of the healthcare professionals to initiate or optimize drug therapy to achieve blood pressure targets [37, 38]. Poor compliance with prescribed medication is another important factor. Education and identifying and addressing the reasons for poor compliance is important to enhance medication adherence $[37,38]$.

In the present study, $62.6 \%, 64.3 \%$ of patients have documented total cholesterol and triglyceride measurement respectively, and about $49 \%$ had documented HDL or LDL measurement. Annual lipid measurement was documented in $34 \%$ in Kuwait, $58 \%$ in Abu Dhabi, and $87 \%$ in Saudi Arabia $[29,31]$. About $51 \%$ of patients had their triglyceride above the target level, and $53.8 \%$ of female patients and $43.5 \%$ of male patients had their HDL cholesterol below the recommended target level. Only $30.8 \%$ of our diabetics had LDL cholesterol of $<100 \mathrm{mg} / \mathrm{dL}$, which meets the ADA goals for LDL cholesterol in diabetics.

Similar rates have been reported from a retrospective study from the United States of America, including data of 7.114 diabetic patients, with goal attainment rates for $\mathrm{LDL}<100 \mathrm{mg} / \mathrm{dL}, \mathrm{HDL}>45 \mathrm{mg} / \mathrm{dL}$, and for triglycerides $<150 \mathrm{mg} / \mathrm{dL}$ at $23 \%, 37 \%$, and $33.8 \%$ respectively [39].

In a retrospective study from Oman including 430 diabetic subjects from six general health centers, the proportion of patients meeting internationally recognized goals for LDL cholesterol, HDL cholesterol and triglycerides were $15 \%, 32 \%$, and $68 \%$ respectively [41].

Despite the evidence base and guideline recommendations for specific preventive screening, such as ophthalmological examination, foot examinations, and screening for microalbuminuria, the documentation of foot examination, eye examination, and screening for microalbuminuria were low, annual testing for protein urea available in only $6.8 \%$ and dilated eye's fundus examination in $3.2 \%$ of patients.

Diabetes needs a multidisciplinary team care approach to improve glycemic control. Nurses can play an important role in patient-oriented care, through education and facilitating of patient adherence to treatment and annual screening procedures.

Diabetes mellitus is a major health problem. International guidelines and evidence recommended standards of care and targets for better outcomes. Challenges for good control lie with effectively implementing them across the population. Continuing audit of diabetes services is an important tool to assess the current practice and highlighting deficiencies and thereby implement strategies to achieve the management goals of a good quality care.

\section{Limitations of this study}

First, the retrospective nature of the study, and the use of medical records to evaluate the care provided and patients' outcomes, depend on the quality of documentation, and may underestimate the actual frequency of screening procedures due to lack of documentation.

Second, factors that influence the outcome like patient's compliance was not evaluated in this study.

\section{Conclusion}

Despite the adaptation of ADA standards of diabetes care at our centre, this study showed that a large number of patients were not achieving the recommended treatment targets. Further studies are needed to find out the causes of the gap between guidelines and practice and help in identifying the barriers to optimal diabetes care. Using a diabetes flow-sheet, which includes all the required targets of diabetes care, as advised by guidelines, would facilitate documentation and disease management.

The role of nurses in diabetes care should be enhanced and nurses involvement in ordering routine laboratory and screening procedures would help ensure that, by the time patients are seen by the doctor, a number of recommended screening procedures have been done.

\section{Conflict of interest}

The authors have no conflicts of interest. 


\section{REFERENCES}

1. Guariguata L, Whiting DR, Hambleton I, et al. Global estimates of diabetes prevalence for 2013 and projections for 2035. Diabetes Res Clin Pract. 2014; 103(2): 137-149, doi: 10.1016/j. diabres.2013.11.002, indexed in Pubmed: 24630390.

2. International diabetes federation (IDF) (2013) IDF Diabetes atlas. edn.6, International diabetes federation, Brussels, Belgium, Europe. Brussels, 2013.

3. Kadiki OA, Roaeid RB. Prevalence of diabetes mellitus and impaired glucose tolerance in Benghazi Libya. Diabetes Metab. 2001; 27(6): 647-654, indexed in Pubmed: 11852372.

4. World Health Organization (2012) STEPwise surveillance of non-communicable disease risk factors in the Eastern Mediterranean region. http://bit.ly/126n6Z1 (accessed 7.6.2013).

5. Stratton IM, Adler Al, Neil HA, et al. Association of glycaemia with macrovascular and microvascular complications of type 2 diabetes (UKPDS 35): prospective observational study. BMJ. 2000; 321(7258): 405-412, doi: 10.1136/bmj.321.7258.405, indexed in Pubmed: 10938048.

6. Forbes JM, Cooper ME. Mechanisms of diabetic complications. Physiol Rev. 2013; 93(1): 137-188, doi: 10.1152/physrev.00045.2011, indexed in Pubmed: 23303908.

7. Brown JB, Pedula KL, Bakst AW. The progressive cost of complications in type 2 diabetes mellitus. Arch Intern Med. 1999; 159(16): 1873-1880, doi: 10.1001/archinte.159.16.1873, indexed in Pubmed: 10493317.

8. da Rocha Fernandes J, Ogurtsova K, Linnenkamp U, et al. IDF Diabetes Atlas estimates of 2014 global health expenditures on diabetes. Diabetes Res Clin Pract. 2016; 117: 48-54, doi: 10.1016/j.diabres.2016.04.016, indexed in Pubmed: 27329022.

9. Seuring T, Archangelidi O, Suhrcke M. The Economic Costs of Type 2 Diabetes: A Global Systematic Review. Pharmacoeconomics. 2015; 33(8): 811-831, doi: 10.1007/s40273-015-0268-9, indexed in Pubmed: 25787932.

10. American Diabetes Association. Economic costs of diabetes in the U.S. in 2012. Diabetes Care. 2013; 36(4): 1033-1046, doi: 10.2337/dc12-2625, indexed in Pubmed: 23468086.

11. Preis SR, Pencina MJ, Hwang SJ, et al. Trends in cardiovascular disease risk factors in individuals with and without diabetes mellitus in the Framingham Heart Study. Circulation. 2009; 120(3): 212-220, doi: 10.1161/CIRCULATIONAHA.108.846519, indexed in Pubmed: 19581493.

12. Lorber D. Importance of cardiovascular disease risk management in patients with type 2 diabetes mellitus. Diabetes Metab Syndr Obes. 2014; 7: 169-183, doi: 10.2147/DMSO.S61438, indexed in Pubmed: 24920930.

13. Nathan DM, Genuth S, Lachin J, et al. Diabetes Control and Complications Trial Research Group. The effect of intensive treatment of diabetes on the development and progression of long-term complications in insulin-dependent diabetes mellitus. N Engl J Med. 1993; 329(14): 977-986, doi: 10.1056/ /NEJM199309303291401, indexed in Pubmed: 8366922

14. UK Prospective Diabetes Study (UKPDS) Group. Intensive bloodglucose control with sulphonylureas or insulin compared with conventional treatment and risk of complications in patients with type 2 diabetes (UKPDS 33). Lancet. 1998; 352(9131): 837-853, indexed in Pubmed: 9742976.

15. UK Prospective Diabetes Study Group. Tight blood pressure control and risk of macrovascular and microvascular complications in type 2 diabetes: UKPDS 38. BMJ. 1998; 317(7160): 703-713, indexed in Pubmed: 9732337.

16. Costa J, Borges M, David C, et al. Efficacy of lipid lowering drug treatment for diabetic and non-diabetic patients: metaanalysis of randomised controlled trials. BMJ. 2006; 332(7550): 1115-1124, doi: 10.1136/bmj.38793.468449.AE, indexed in Pubmed: 16585050

17. Marshall SM, Flyvbjerg A. Prevention and early detection of vascular complications of diabetes. BMJ. 2006; 333(7566):
475-480, doi: 10.1136/bmj.38922.650521.80, indexed in Pubmed: 16946335.

18. Mayfield JA, Reiber GE, Sanders $\amalg$, et al. Preventive Foot Care in People With Diabetes. Diabetes Care. 1998; 21(12): 2161-2177, doi: 10.2337/diacare.21.12.2161, indexed in Pubmed: 9839111.

19. Gross JL, Azevedo MJde, Silveiro SP, et al. Diabetic Nephropathy: Diagnosis, Prevention, and Treatment. Diabetes Care. 2004; 28(1): 164-176, doi: 10.2337/diacare.28.1.164, indexed in Pubmed: 15616252.

20. Bragge $P$, Gruen RL, Chau M, et al. Screening for presence or absence of diabetic retinopathy: a meta-analysis. Arch Ophthalmol. 2011; 129(4): 435-444, doi: 10.1001/archophthalmol.2010.319, indexed in Pubmed: 21149748.

21. American Diabetes Association. American Diabetes Association Standards of Medical Care in Diabetes - 2017. Diabetes Care. 2017; 40(suppl 1): S1-S138.

22. Grant RW, Buse JB, Meigs JB, et al. University HealthSystem Consortium (UHC) Diabetes Benchmarking Project Team. Quality of diabetes care in U.S. academic medical centers: low rates of medical regimen change. Diabetes Care. 2005; 28(2): 337-442, doi: 10.2337/diacare.28.2.337, indexed in Pubmed: 15677789.

23. Cooper JG, Claudi T, Jenum AK, et al. Quality of care for patients with type 2 diabetes in primary care in Norway is improving: results of cross-sectional surveys of 33 general practices in 1995 and 2005. Diabetes Care. 2009; 32(1): 81-83, doi: 10.2337/dc080605, indexed in Pubmed: 18852338.

24. Laxy M, Knoll G, Schunk M, et al. Quality of Diabetes Care in Germany Improved from 2000 to 2007 to 2014, but Improvements Diminished since 2007. Evidence from the Population-Based KORA Studies. PLoS One. 2016; 11(10): e0164704, doi: 10.1371/journal. pone.0164704, indexed in Pubmed: 27749939.

25. Alhyas L, McKay A, Balasanthiran A, et al. Quality of type 2 diabetes management in the states of the Co-operation Council for the Arab States of the Gulf: a systematic review. PLoS One. 2011; 6(8): e22186, doi: 10.1371/journal.pone.0022186, indexed in Pubmed: 21829607.

26. Cagliero E, Levina EV, Nathan DM. Immediate feedback of HbA1c levels improves glycemic control in type 1 and insulin-treated type 2 diabetic patients. Diabetes Care. 1999; 22(11): 1785-1789, doi: 10.2337/diacare.22.11.1785, indexed in Pubmed: 10546008.

27. Larsen ML, Hørder M, Mogensen EF. Effect of long-term monitoring of glycosylated hemoglobin levels in insulin-dependent diabetes mellitus. N Engl J Med. 1990; 323(15): 1021-1025, doi: 10.1056/NEJM199010113231503, indexed in Pubmed: 2215560.

28. Yang S, Kong W, Hsue C, et al. Knowledge of A1c Predicts Diabetes Self-Management and A1c Level among Chinese Patients with Type 2 Diabetes. PLoS One. 2016; 11(3): e0150753, doi: 10.1371/journal.pone.0150753, indexed in Pubmed: 26959422.

29. Badawi D, Saleh S, Natafgi N, et al. Quality of Type II Diabetes Care in Primary Health Care Centers in Kuwait: Employment of a Diabetes Quality Indicator Set (DQIS). PLoS One. 2015; 10(7): e0132883, doi: 10.1371/journal.pone.0132883, indexed in Pubmed: 26176691.

30. Akel M, Hamadeh G. Quality of diabetes care in a university health center in Lebanon. Int J Qual Health Care. 1999; 11(6): 517-521, doi: 10.1093/intqhc/11.6.517, indexed in Pubmed: 10680948.

31. Kharal M, Al-Hajjaj A, Al-Ammri M, et al. Meeting the American Diabetic Association standards of diabetic care. Saudi J Kidney Dis Transpl. 2010; 21(4): 678-685, indexed in Pubmed: 18445910.

32. Al-Elq AH. Current practice in the management of patients with type 2 diabetes mellitus in Saudi Arabia. Saudi Med J. 2009; 30(12): 1551-1556, indexed in Pubmed: 19936419.

33. Alhyas L, Cai Y, Majeed A. Type 2 diabetes care for patients in a tertiary care setting in UAE: a retrospective cohort study. JRSM Short Rep. 2012; 3(10): 67, doi: 10.1258/shorts.2012.012064, indexed in Pubmed: 23162680.

34. Al-Hussein F. Diabetes control in a primary care setting: a retrospective study of 651 patients. Ann Saudi Med. 2008; 28(4): 
267-271, doi: 10.5144/0256-4947.2008.267, indexed in Pubmed: 18596404.

35. Saydah SH, Fradkin J, Cowie CC. Poor control of risk factors for vascular disease among adults with previously diagnosed diabetes. JAMA. 2004; 291(3): 335-342, doi: 10.1001/jama.291.3.335, indexed in Pubmed: 14734596.

36. Turner RC, Cull CA, Frighi V, et al. Glycemic control with diet, sulfonylurea, metformin, or insulin in patients with type 2 diabetes mellitus: progressive requirement for multiple therapies (UKPDS 49). UK Prospective Diabetes Study (UKPDS) Group. JAMA. 1999; 281(21): 2005-2012, indexed in Pubmed: 10359389.

37. Schmittdiel JA, Uratsu CS, Karter AJ, et al. Why don't diabetes patients achieve recommended risk factor targets? Poor adherence versus lack of treatment intensification. J Gen Intern Med. 2008; 23(5): 588-594, doi: 10.1007/s11606-008-0554-8, indexed in Pubmed: 18317847.
38. TRIAD Study Group. Health Systems, Patients Factors, and Quality of Care for Diabetes: A synthesis of findings from the TRIAD Study. Diabetes Care. 2010; 33(4): 940-947, doi: 10.2337/dc09-1802, indexed in Pubmed: 20351230.

39. Beaton SJ, Nag SS, Gunter MJ, et al. Adequacy of glycemic, lipid, and blood pressure management for patients with diabetes in a managed care setting. Diabetes Care. 2004; 27(3): 694-698, doi: 10.2337/diacare.27.3.694, indexed in Pubmed: 14988287.

40. Cushman WC, Evans GW, Byington RP, et al. ACCORD Study Group. Effects of intensive blood-pressure control in type 2 diabetes mellitus. N Engl J Med. 2010; 362(17): 1575-1585, doi: 10.1056/ /NEJMoa1001286, indexed in Pubmed: 20228401.

41. Al-Mandhari A, Al-Zakwani I, El-Shafie O, et al. Quality of Diabetes Care: A cross-sectional observational study in Oman. Sultan Qaboos Univ Med J. 2009; 9(1): 32-36, indexed in Pubmed: 21509272. 